\title{
Persepsi Mahasiswa Terhadap Pemanfaatan Aplikasi Sensor Smartphone untuk Praktikum
}

\author{
Rizalul Fiqry \\ STKIP Taman Siswa Bima, Kabupaten Bima, Nusa Tenggara Barat \\ E-mail: doudonggo@gmail.com
}

\begin{abstract}
Article Info
Students' perceptions about the use of Smartphone sensor applications as a practicum

Article History

Received: 2021-01-12

Revised: 2021-02-01

Published: 2021-03-10

Keywords:

Smartphone Sensor;

Student Perception;

Independent Practicum;

Phyphox.

Abstract media are described in this study. The type of research is descriptive research with a survey method of 9 students of the Physics Education STKIP Taman Siswa Bima class of 2017. The data collection technique used a questionnaire with the Google Form application. The steps of this research: (1) preparation of a Google Form questionnaire instrument, (2) Validation of the questionnaire using experts. (3) collecting data with a validated questionnaire, (4) analyzing the data descriptively. The results showed that the students of STKIP Taman Siswa Bima Physics Education class of 2017 knew about the Smartphone sensor application. This application is also considered to be very helpful for students in doing practicum independently. In addition, the use of this application also has great benefits for increasing student motivation, especially during the Covid-19 pandemic. However, to use this application requires training first and must be equipped with modules and teaching materials to make it easier for students to apply them.
\end{abstract}

\begin{abstract}
Abstrak
Persepsi mahasiswa terhadap pemanfaatan aplikasi sensor Smartphone sebagai media praktikum diungkap dalam penelitian ini. Jenis penelitian yang digunakan yaitu kajian deskriptif dengan dengan metode survey terhadap mahasiswa Pendidikan Fisika STKIP Taman Siswa Bima angkatan 2017 sebanyak 9 orang. Teknik pengumpulan data dengan menggunakan angket yang dibuat dengan Google Form. Tahapan yang dilakukan dalam penelitian ini adalah: (1) penyusunan instrumen angket Google Form, (2) angket kemudian diuji validitas dengan menggunakan pandangan ahli. (3) mengumpulkan data dengan angket yang telah divalidasi, (4) analisis data secara deskriptif. Dari penelitian dan analisis yang dilakukan, didapatkan hasil bahwa aplikasi sensor Smartphone sudah dikenal oleh mahasiswa Pendidikan Fisika STKIP Taman Siswa Bima angkatan 2017. Aplikasi tersebut juga dirasa sangat membantu mahasiswa dalam melakukan praktikum secara mandiri. Selain itu, penggunaan aplikasi tersebut juga memiliki manfaatkan yang besar untuk meningkatkan motivasi belajar mahasiswa terutama pada masa pandemi Covid-19. Hanya saja, pemanfaatan aplikasi tersebut perlu diadakan pelatihan sebelumnya dan perlu dilengkapi dengan modul dan bahan ajar agar lebih mudah dipahami oleh mahasiswa.
\end{abstract}

\section{PENDAHULUAN}

Perkembangan teknologi dewasa ini tidak terbendung. Begitu banyak program yang diciptakan untuk keperluan pertahanan keamanan, perindustrian, lingkungan, pertanian, kesehatan dan pendidikan (Irfan et al., 2017). Memasuki era revolusi industry 4.0 terjadi perubahan mindset social tentang digitalisasi teknologi (Ghufron, 2018), bisa dikatakan bahwa era teknologi telah masuk sampai ke bagian terdekat dengan manusia (Ngafifi, 2014), salah satunya pada proses Pendidikan. Pemanfaatan teknologi sangat dirasakan pada proses pendidikan dewasa ini, teknologi dapat mempermudah proses pembelajaran sebagai media pendukung pembelajaran dan sarana untuk mendapatkan informasi sehingga mampu meningkatkan kualitas pendidikan. Hal ini sejalan dengan pernyataan Makiyah et al. (2019) bahwa penggunaan teknologi sebagai media pembelajaran akan membantu peningkatan keterampilan abad 21.

Pemanfaatan Smartphone menjadi salah satu pilihan sebagai media pembelajaran yang paling diminati dewasa ini. Smartphone menyediakan banyak aplikasi yang dapat digunakan dalam pembelajaran baik yang berbasis Learning Management System (LMS) maupun yang berbasis sensor. Aplikasi-aplikasi ini memiliki keunggulan, antara lain interaktif, fleksibel dan mudah dalam pengoperasiannya. 
Aplikasi sensor Smartphone banyak dimanfaatkan dalam mempelajari materi Fisika di antaranya Sensor Tracker, Science Journal, Phyphox, Accelerometer Counter dan masih banyak lagi jenisnya. Pemanfaatan aplikasi-aplikasi ini memudahkan untuk mempelajari konsep Fisika secara kontekstual. Selain itu, ketersediaan aplikasi-aplikasi ini sangat dirasakan manfaaanya di masa pandemi Covid-19 sekarang ini, terutama pada matakuliah Eksperimen Fisika.

Mempelajari Fisika tidak hanya pada tataran konsep tetapi juga perlu mengembangkan keterampilan, akan tetapi proses pembelajaran menjadi terbatas karena diberlakukan perkuliahan secara daring sehingga kegiatan praktikum yang sejatinya dilakukan di laboratorium tidak dapat dilaksanakan. Maka sebagai solusinya, mahasiswa diarahkan untuk melakukan praktikum secara mandiri dengan memanfaatkan aplikasi-aplikasi sensor yang tersedia pada Smartphone dengan tetap dalam bimbingan dosen pengampu matakuliah. Menggunakan metode praktikum seperti ini menjelaskan bahwa teknologi mampu menjadi solusi di masa pandemi Covid-19 yang tengah dihadapi saat ini (Khasanah et al., 2020).

Pemanfatan aplikasi sensor Smartphone perlu dikaji keefektifannya dari perspektif mahasiswa sebagai pengguna, khususnya aplikasi-aplikasi yang digunakan pada matakuliah Eksperimen Fisika yaitu Phyphox (Physical Phone Experiments) dan Science Journal. Aplikasi ini menyediakan layanan berupa sensor yang memungkinkan untuk memantau gerakan Smartphone (Nurfadilah et al., 2019). Persepsi mahasiswa akan menjadi tolak ukur pemanfaatan aplikasi-aplikasi ini kedepannya dan pengembangan bahan ajar.

\section{METODE PELAKSANAAN}

Penelitian yang dilakukan merupakan jenis penelitian deskriptif, dengan melakukan survey terhadap mahasiswa pendidikan Fisika STKIP Taman Siswa Bima angkatan 2017 yang memprogram matakuliah Eksperimen Fisika sebanyak 9 orang. Teknik pengumpulan data dengan menggunakan angket persepsi mahasiswa dengan media Google Form.

Tahapan yang dilakukan dalam penelitian ini adalah: 1) Menyusun angket dengan memanfaatkan Google Form yang memuat informasi sebagai berikut: pengetahuan tentang aplikasi Smartphone yang bisa digunakan untuk praktikum, pengetahuan tentang penggunaan aplikasi, jenis aplikasi sensor android yang pernah digunakan, pendapat tentang penggunaan praktikum menggunakan Smartphone, manfaat pengunaan aplikasi interaktif sensor android, kemudahan memahami materi kuliah melalui praktikum menggunakan sensor android, kemudahan memahami menu aplikasi, cara mengoperasikan aplikasi, perlunya penerapan menggunakan modul, perlunya bahan ajar atau sumber belajar, perlunya untuk melakukan pelatihan penggunaan aplikasi, dan pandangan tentang manfaat aplikasi. 2) Angket didistribusikan kepada mahasiswa. 3) Melakukan analisis data secara deskriptif yaitu menjabarkan presepsi mahasiswa berdasarkan prosentasi jawaban yang diberikan dalam angket.

\section{HASIL DAN PEMBAHASAN}

Presepsi mahasiswa tentang penggunaan aplikasi sensor Smartphone untuk praktikum direpresentasikan dengan data yang diperoleh melalui angket Google Form. Jumlah responden sebanyak 9 orang. Dari 9 responden, sebanyak $78 \%$ mahasiswa sudah pernah menggunakan aplikasi interaktif yang tersedia pada Smartphone. Distribusi data seperti pada gambar berikut:

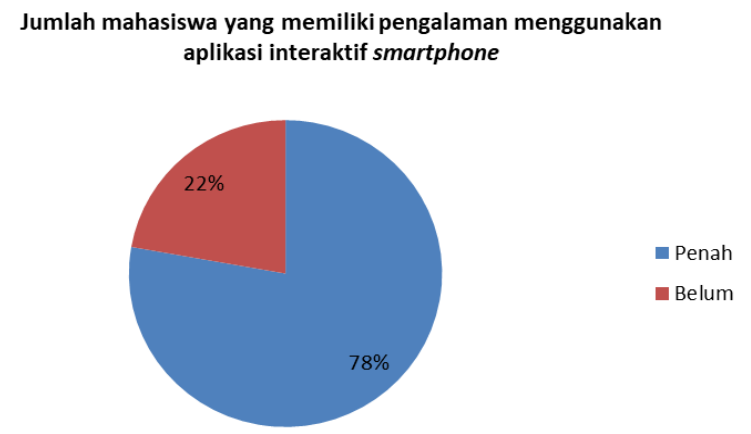

Gambar 1. Jumlah mahasiswa yang memiliki pengalaman dalam menggunakan aplikasi interaktif Smartphone.

Mahasiswa memperoleh informasi tentang aplikasi-aplikasi tersebut dari dosen melalui matakuliah Ekseperimen Fisika dan juga dari hasil pencarian secara mandiri melalui Google dan YouTube. Seluruh mahasiswa juga mengetahui bahwa banyak aplikasi yang tersedia yang dapat digunakan sebagai media praktikum, distribusi data seperti yang tertera pada gambar berikut:

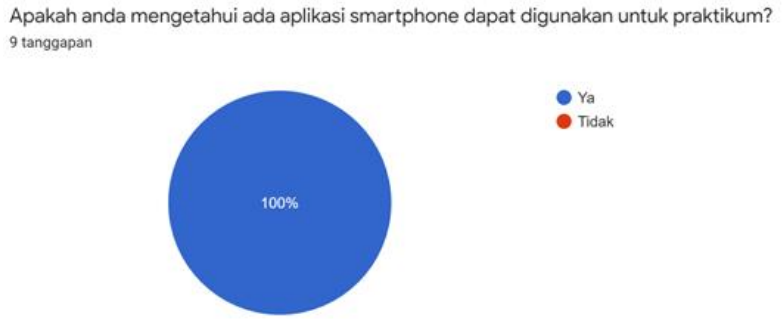

Gambar 2. Analisis pengetahuan mahasiswa tentang aplikasi android

Mahasiswa sudah memiliki pemahaman yang baik tentang aplikasi sensor Smartphone. Hal ini ditandai dengan pengetahuan awal mahasiswa tentang manfaat aplikasi-aplikasi tersebut dalam pembelajaran yaitu membantu melakukan praktikum secara mandiri, membantu mengkontekstualkan materi pembelajaran, dan menyederhanakan kegiatan praktikum karena tidak membutuhkan peralatan yang banyak. Selain itu, pengetahuan mahasiswa terhadap 
pemanfaatan aplikasi sensor Smartphone dalam pembelajaran menandakan mahasiswa sudah mampu beradaptasi dengan perkembangan teknologi Era 4.0 dan tuntutan keterampilan abad 21 salah satunya mahasiswa harus memiliki kemampuan belajar secara mandiri.

Jumlah mahasiswa yang sudah pernah menggunakan aplikasi sensor Smartphone untuk pembelajaran yaitu sebanyak 77,8\% sedangkan yang belum pernah menggunakan sebanyak $22,2 \%$, seperti yang tertera pada gambar berikut:

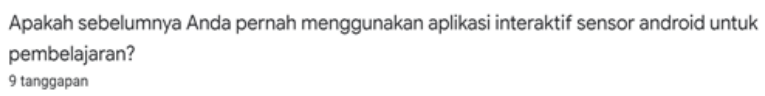

Gambar 3. Analisis pengalaman menggunakan aplikasi

Porsentase mahasiswa yang pernah menggunakan aplikasi sensor Smartphone lebih besar dibanding yang belum pernah menggunakan, ini menandakan kesadaran mahasiswa terhadap perkembangan teknologi dalam pembelajaran semakin tinggi dan adanya pergeseran cara pandang tentang dunia pendidikan, terutama di bidang sains. Salah satunya pada kegiatan praktikum. Ketersediaan banyak aplikasi dengan sarana sensor pada Smartphone sebagai media praktikum mempermudah proses praktikum. Kegiatan praktikum tidak lagi terbatas dilakukan di Laboratorium (Anjum \& Ilyas, 2013; Henik Istikhomah, Indarto A.S, 2014; Nisa, 2012; Nurfadilah et al., 2019).

Jenis aplikasi sensor Smartphone yang tersedia cukup beragam, namun tidak semua diketahui atau digunakan oleh mahasiswa. Ada beberapa aplikasi populer di kalangan mahasiswa di antaranya Phyphox, Physics Vitual Lab, Science Journal, Sensor Lab, Kalkulator Fisika dan Sensor Kinetics seperti yang tertera pada gambar berikut:

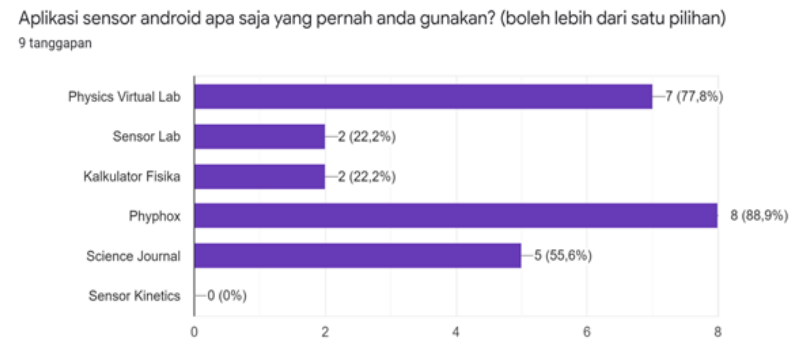

Gambar 4. Analisis jenis aplikasi yang pernah digunakan mahasiswa

Phyphox dan Physics Vitual Lab menjadi aplikasi paling banyak digunakan oleh mahasiswa karena aplikasi ini memiliki keunggulan variable pengukuran sebagian besar terbaca oleh sensor dan data pengukurannya ditampilkan secara grafis.

Tingkat pemanfaatan aplikasi sensor Smartphone menurut pandangan mahasiswa dapat dilihat pada gambar 5, gambar 6 dan gambar 7. Dari data tersebut menunjukkan betapa pemanfaatan aplikasi sangat membantu mahasiswa dalam memahami fenomena fisika yang terjadi dan membantu meningkatkan pemahaman konsep. Karena pada saat praktikum mahasiswa dapat melihat langsung gejala beserta besar fisis yang bekerja. (Agustine et al., 2014; Kurniawan et al., 2020).

Apakah Anda setuju jika praktikum dilakukan dengan memanfaatkan aplikasi sensor smerthhone? 9 tanggapan

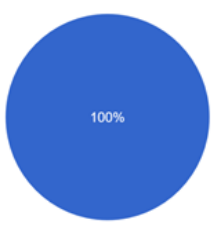

Y Ya

Gambar 5. Analisis pendapat tentang manfaat aplikasi

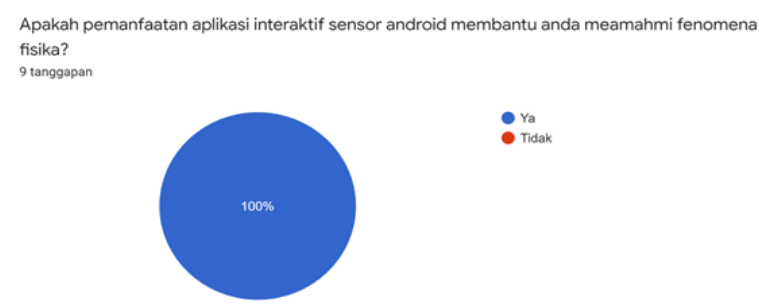

Gambar 6. Analisis pemanfaatan aplikasi sensor android

Apakah aplikasi interaktif sensor android memudahkan dalam memahami materi perkuliahan? 9 tanggap

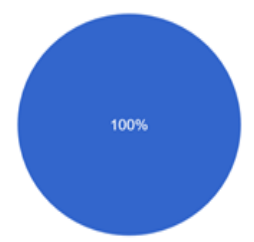

Ya

Gambar 7. Analisis pendapat tentang aplikasi sensor android untuk mempermudah pemahaman mahasiswa

Dari aspek penggunaan, 88,9\% mahasiswa mampu memahami penggunaan menu-menu pada aplikasi secara mandiri dan $11,1 \%$ mahasiswa merasa kesulitan dalam menggunakan menu-menu pada aplikasi. Distribusi jawaban mahasiswa dapat dilihat pada gambar 8 dan gambar 9 berikut ini: 
Apakah penggunaan menu-menu dalam aplikasi interaktif sensor android mudah dipahami? 9 tanggapan

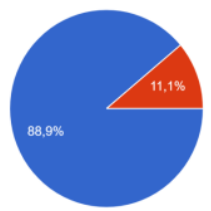

$$
\text { - Ya }
$$

Gambar 8. Kemudahan penggunaan aplikasi

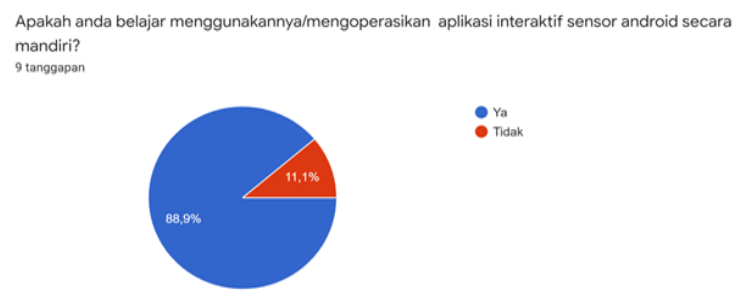

Gambar 9. Analisis penggunaan sensor dilakukan secara mandiri

Meskipun sebagian besar mahasiswa mampu menggunakan aplikasi secara mandiri, akan tetapi mahasiswa merasa membutuhkan Modul sebagai panduan saat melakukan praktikum. Modul menjadi acuan mahasiswa saat melakukan praktikum agar terstruktur, baik berdasarkan tujuan pembelajarannya maupun penggunaan aplikasinya (Pratiwi et al., 2018; Saparini et al., 2018).

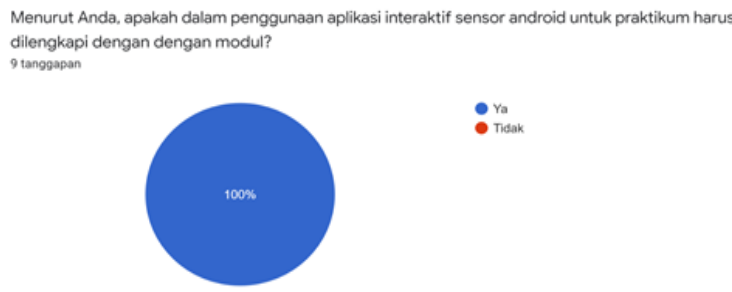

Gambar 10. Analisis pendapat penggunaan aplikasi sensor android harus dengan modul

Selain perlunya ketersediaan modul, menurut 88,9\% mahasiswa ketersediaan bahan ajar atau sumber belajar saat praktikum menjadi hal yang tidak kalah penting. Data tersebut ditujukkan pada gambar berikut:

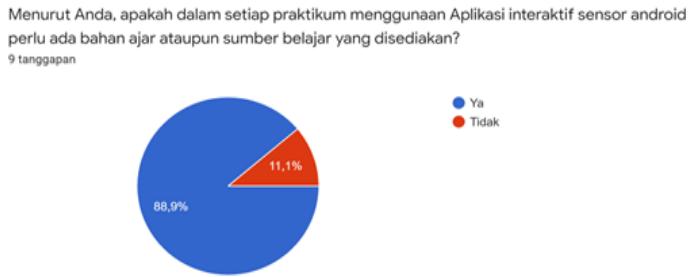

Gambar 11. Analisis pendapat mahasiswa disetiap praktikum perlu ada bahan/sumber ajar yang disedikan
Menurut 88,9\% mahasiswa, hal penting yang perlu dilakukan sebelum menerapkan aplikasi interaktif tersebut dalam proses pembelajaran perlu dilakukan pelatihan.

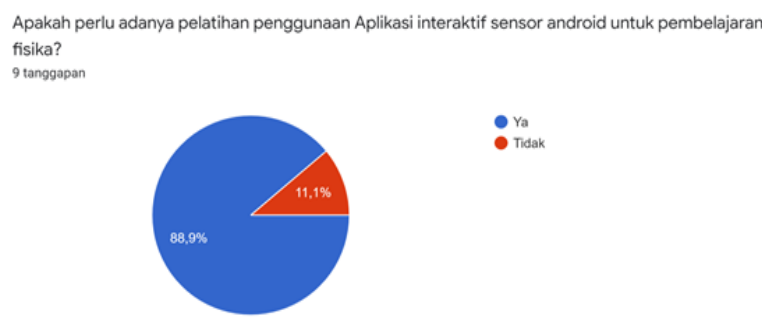

Gambar 12. Analisis pendapat mahasiswa perlunya dilakukan pelatihan penggunaan aplikasi sensor android

Harapan utama saat menerapkan aplikasiaplikasi interaktif dalam proses pembelajaran yaitu mahasiswa dapat belajar secara mandiri. Respon $100 \%$ mahasiswa menyatakan setuju bahwa penggunaan aplikasi tersebut membantu proses belajar mandiri (gambar 13). Dari sisi motivasi, $100 \%$ mahasiswa setuju jika pembelajaran dengan menggunaka aplikasi Smartphone berbasis sensor ini dapat meningkatkan motivasi dalam belajar (gambar 14) Sehingga $100 \%$ responden menyimpulkan bahwa aplikasi bermanfaat dalam proses pembelajaran.

Apakah Aplikasi interaktif sensor android membantu Anda dalam belajar secara mandiri? 9 tanggapan

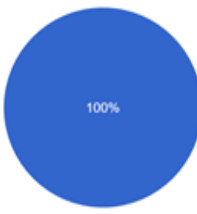

$$
\bullet \text { Ya }
$$

Gambar 13. Analisis pendapat mahasiswa tentang aplikasi sensor android membantu proses belajar mandiri

Apakah pembelajaran dengan memanfaatkan Aplikasi interaktif sensor android meningkatkan motivasi Anda dalam belajar? 9 tanggapan

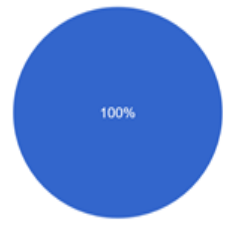

$\because$ Ya

Gambar 14. Analisis pembelajaran dengan memanfaatkan android dapat meningkatkan motivasi belajar 


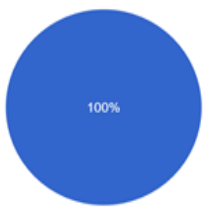

\section{Yidak}

Gambar 15. Analisis aplikasi sensor andoroid bermanfaat dalam proses pembelajaran

Hasil survey menunjukkan sebagian besar mahasiswa sadar akan tersedianya aplikasi-aplikasi berbasis sensor pada Smartphone. Mahasiswa juga memahami manfaat aplikasi-aplikasi tersebut dapat mempermudah proses praktikum Fisika terutama menjadi solusi praktikum di masa pandemi Covid-19 ini.

Pemanfaatan aplikasi-aplikasi ini dapat meningkatkan kemandirian, motivasi dan keterampilan abad 21 bagi mahasiswa. Karena dalam penerapannya mahasiswa melakukan praktikum secara mandiri, mahasiswa juga termotivasi untuk terus mempelajari konsep fisika melalui aplikasi tersebut baik secara mandiri, browsing informasi, maupun berdiskusi dengan teman dan dosen. Keterampilan abad 21 juga ikut meningkat diantaranya: keterampilan sosial-kultur, keterampilan berpikir kritis dan kreatif dalam bermetakognisi dan pemecahan masalah, literasi komunikasi dan teknologi untuk dapat menggali informasi, dan produktivitas dalam mengorganisir dan melaksanakan penelitian secara efektif dan efisien. Keempat keterampilan abad 21 yang memang perlu dimiliki oleh mahasiswa (Voogt \& Roblin, 2012).

Akan tetapi yang perlu menjadi catatan dalam pemanfaatan aplikasi-aplikasi ini dalam pembelajaran yaitu perlunya pelatihan sebelum menerapkannya dalam pembelajaran dan penerapannya perlu disertakan modul praktikum dan bahan ajar.

\section{SIMPULAN DAN SARAN}

\section{A. Simpulan}

Dari penelitian dan analisis yang dilakukan, didapatkan hasil bahwa aplikasi sensor android sudah dikenal oleh mahasiswa pendidikan fisika STKIP Taman Siswa Bima angkatan 2017. Aplikasi tersebut juga dirasa sangat membantu mahasiswa dalam melakukan praktikum mandiri. Selain itu, penggunaan aplikasi tersebut juga memiliki manfaatkan yang besar untuk meningkatkan motivasi belajar siswa terutama pada masa pandemi Covid-19. Hanya saja, perlu dibuatkan pelatihan dan tersedianya buku ajar/bahan ajar agar lebih dapat dipahami lagi oleh mahasiswa.

\section{B. Saran}

Adapun saran yang dapat disampaikan berdasarkan hasil penelitian tindakan ini, yaitu: (1) Sebelum menerapkan aplikasi Smartphone bebrasis sensor dalam pembelajaran perlu adanya kegiatan pelatihan atau pengenalan aplikasi kepada mahasiswa, (2) Perapkan aplikasi Smartphone bebrasis sensor dalam pembelajaran perlu dilengkapi dengan modul praktikum, (3) Penelitian berikutnya dapat mengkaji pengaruh penerapan aplikasi Smartphone berbasis sensor terhadap keterampilan abad 21.

\section{DAFTAR RUJUKAN}

Agustine, D., Wiyono, K., \& Muslim, M. (2014). Pengembangan e-learning Berbantuan Virtual Laboratory untuk Mata Kuliah Praktikum Fisika Dasar II di Program Studi Pendidikan Fisika FKIP UNSRI. Jurnal Inovasi Dan Pembelajaran Fisika, Vol. 1, No. 1.

Anjum, A., \& Ilyas, M. U. (2013). Activity Recognition using Smartphone Sensors. 2013 IEEE 10th Consumer Communications and Networking Conference, CCNC 2013. 11-14 January 2013, DOI:

https://doi.org/10.1109/CCNC.2013.6488584

Ghufron, G. (2018). Revolusi Industri 4.0: Tantangan, Peluang, Dan Solusi Bagi Dunia Pendidikan. Seminar Nasional Dan Diskusi Panel Multidisiplin Hasil Penelitian Dan Pengabdian Kepada Masyarakat 2018, Vol. 1, No. 1.

Henik Istikhomah, Indarto A.S, D. T. P. . (2014). Persepsi Mahasiswa Tentang Media Pembelajaran E-Learning Students Perception EElearning In Obstetrics Departement. Jurnal Ilmu Kebidanan, Vo. 2, No. 2.

Irfan, Rasdiansyah, \& Munadi, M. (2017). Jurnal Teknologi dan Industri Pertanian Indonesia. Jurnal Teknologi Dan Industri Pertanian Indonesia, Vo. 9, No.1.

Khasanah, D. R. A. U., Pramudibyanto, H., \& Widuroyekti, B. (2020). Pendidikan Dalam Masa Pandemi Covid-19. Jurnal Sinestesia, Vo. 22, No. 1.

Kurniawan, R. A., Rifa'i, M. R., \& Fajar, D. M. (2020). Analisis Kemenarikan Media Pembelajaran Phet Berbasis Virtual Lab pada Materi Listrik Statis Selama Perkuliahan Daring Ditinjau dari Perspektif Mahasiswa. Jurnal Pendidikan IPA, Vo. 1. No 1.

Makiyah, Y. S., Malik, A., Susanti, E., \& Mahmudah, I. R. (2019). Higher Order Thinking Real and Virtual Laboratory ( HOTRVL) untuk Meningkatkan Keterampilan Abad Ke-21 Mahasiswa Pendidikan Fisika. Diffraction, Vol. 1. No. 1.

Ngafifi, M. (2014). Kemajuan Teknologi dan Pola Hidup Manusia dalam Perspektif Sosial Budaya. Jurnal Pembangunan Pendidikan: Fondasi Dan 
Aplikasi, Vol. 2. No. 1. DOI: https://doi.org/10.21831/jppfa.v2i1.2616

Nurfadilah, N., Ishafit, I., Herawati, R., \& Nurulia, E. (2019). Pengembangan Panduan Eksperimen Fisika Menggunakan Smarthphone dengan Aplikasi Phyphox Pada Materi Tumbukan. Jurnal Penelitian Pembelajaran Fisika. Vo. 10. No. 2. DOI: https://doi.org/10.26877/jp2f.v10i2.4019

Pratiwi, D., Astutik, S., \& Maryani, M. (2018). Model Pembelajaran Collaborative Creativity (CC) Berbantuan Virtual Laboratory pada Pembelajaran Fisika di SMA. Jurnal Pembelajaran Fisika, Vol. 10. No. 1.
Saparini, S., Wiyono, K., \& Ismet, I. (2018). Pengembangan Lembar Kerja Mahasiswa Berbasis Inkuiri Untuk Melaksanakan Praktikum Secara Virtual Laboratory Pada Materi Listrik Dinamis. Berkala Ilmiah Pendidikan Fisika. Vol. 6. No. 1. DOI: https://doi.org/10.20527/bipf.v6i1.4401

Voogt, J., \& Roblin, N. (2012). A comparative analysis of International Frameworks for 21st Century Competencies: Implications for National Curriculum Policies. Journal of Curriculum Studies, 44(3), 299-321. 